\title{
DIREITOS FUNDAMENTAIS, DIREITO TRIBUTÁRIO E ANÁLISE ECONÔMICA DO DIREITO: CONTRIBUIÇÕES E LIMITES
}

\author{
PAULO CALIENDO*
}

RESUMO: Pretende o presente texto verificar as relações entre o estudo da denominada análise econômica do Direito e o Direito Tributário, bem como as contribuições que podem surgir desta pesquisa. Objetiva, especialmente, verificar como a análise econômica do Direito Tributário pode auxiliar na busca da efetividade do financiamento dos Direitos Fundamentais. PALAVRAS-CHAVE: Análise Econômica do Direito Tributário; Concretização dos Direitos Fundamentais; Tributação.

\begin{abstract}
The present text intends to verify the relationships between the study of the so called economical analysis of Law and that of Taxation Law, as well as the contributions that may arise from such investigation. It aims especially at verifying how the economical analysis of Taxation Law may help in the search for the effectiveness of Fundamental Rights financing.
\end{abstract}

KEYWORDS: Law and Economics; Human Rights; Taxation.

SUMÁRIO: 1. Pressupostos Metodológicos; 2. Origem e escolas de pensamento; 2.1. Metodologia; 2.2. Crítica da análise econômica do Direito; 3. Análise econômica da Tributação; 3.1. Teorema de Coase: a tributação como custo de transação; 3.2. Os custos de transação; 3.3. A tributação e os custos de transação; 3.4. A Nova Economia Institucional (New Institutional Economics): tributação como instituição; 3.5. Contribuições da Nova Economia Institucional (New Institutional Economics); 3.6. Contribuições da Nova Economia Institucional (New Institutional Economics) para a compreensão do fenômeno da tributação; 4. O problema da eficiência; $4.1 \mathrm{O}$ debate entre Dworkin e Posner sobre a justiça e a eficiência; 4.2. As normas jurídicas como instrumento de eficiência econômica; 4.3. Eficiência (efficiency) e distribuição de renda (income distribution); 4.4. Neutralidade econômica da tributação; 5. Considerações Finais; 6. Referências Bibliográficas.

SUMMARY: 1. Methodological Premises; 2. Origin and Schools of Thought; 2.1. Methodology; 2.2. Critic of the economical analysis of Law; 3. Economical analysis of Taxation; 3.1. Coase Theorem: taxation as transaction cost; 3.2. The costs of transaction; 3.3. Taxation and the transaction costs; 3.4. New Institutional Economics: taxation as institution; 3.5. New Institutional Economics' contributions; 3.6. New Institutional Economics' contributions for the taxation phenomenon's comprehension; 4. The efficiency problem; 4.1 The Dworkin-Posner debate on justice and efficiency; 4.2. Legal norms as economical efficiency instruments; 4.3. Efficiency and income distribution; 4.4. Taxation's economical neutrality; 5. Final considerations; 6. Bibliographical references.

Artigo recebido em 6.04.2009 e aprovado para publicação pelo Conselho Editorial em 23.06.2009.

* Professor do Mestrado e Doutorado da PUCRS. Doutor pela PUC-SP e com doutorado-sandwich na Universidade de Munique, na Alemanha. Árbitro do Mercosul pela lista brasileira. 


\section{PRESSUPOSTOS METODOLÓGICOS}

Uma teoria sistêmica da tributação para ser consistente deveria considerar que:

a. Fenômeno sistêmico: A tributação é um fenômeno intersistêmico que envolve a Política, a Economia e o Direito. No caso da política pode ser lido como uma relação entre poder e não poder (limites) tributar, ou seja, exigir prestações pecuniárias compulsórias de particulares; no caso da economia a tributação pode ser entendida como um elemento relativo à programação dos agentes econômicos sobre o que terão ou não nas situações de produção, acumulação e circulação de bens em uma dada sociedade. Por sua vez, o Direito irá considerá-la como conjunto de expectativas institucionalizadas que dizem como os outros se comportem nas relações entre o poder de tributar e as limitações a este poder, determinando as sanções pelo descumprimento dessas normas condicionais.

b. Complexidade e evolução: o Sistema Tributário deve ser lido como o resultado das trocas entre os subsistemas da sociedade e dessa forma terá o sentido dinâmico de resposta à complexidade do sistema social e ao risco; bem como a incapacidade de previsão exata de consequências racionais para as programações em matéria tributária exigirá a adaptação às novas condições e a permanente evolução do sistema tributário.

c. Equilíbrio: as trocas entre os diversos subsistemas deverá ser realizado de modo equilibrado, de tal forma que não ocorra a "corrupção" do sistema, ou seja, a imposição do código binário de um subsistema em outro subsistema, de tal forma que o próprio resultado final seja afetado. Assim, por exemplo, se houvesse a prevalência da Economia sobre o jurídico o sentido de tributação poderia corresponder a ditames econômicos e o próprio Direito seria incapaz de ter uma leitura própria do fenômeno e assim a necessária identidade interna construída por diferenciação seria ferida de morte. Tal leitura se torna ainda mais radical para aqueles que vêm a justiça ocupando um papel de destaque no Direito ${ }^{1}$ e, desse modo, poderíamos ver a justiça cedendo espaço para exigências de eficiência econômica.

d. Princípios jurídicos: O princípio da neutralidade fiscal e da capacidade contributiva poderiam ser lidos, neste sentido, como o modo do sistema jurídico proceder o correto filtro para as informações advindas do subsistema da economia sobre a tributação e, assim, indicar como devem ser programadas as expectativas dos agentes. O sentido e o alcance do princípio da neutralidade fiscal somente seria possível verificando-se cada sociedade em particular.

e. Conflito entre princípios: Torna-se claro que equidade e eficiência entrem geralmente em conflito em termos econômicos. O princípio da neutralidade fiscal e da capacidade contributiva representam no âmbito jurídico esta tentativa de ponderar estes dois interesses distintos.

\section{ORIGEM E ESCOLAS DE PENSAMENTO}

O movimento denominado de análise econômica do Direito (Law and Economics) se constitui em uma alternativa à filosofia moral e política do utilitarismo que era

${ }^{1}$ Nesse sentido, ver Tipke: „Da Steuern in einem Rechtsstaat gereecht verteilt werden müssen, gilt der Primat der Ethik. D. h. In einem Rechtsstaat gehört das Gerechtigkeitskriterium nach vor“; ver in Tipke, Klaus. Die Steuerrechtsordnung. 2. Auf., Köln: Dr. Otto Schmidt, 2003, p. 591. 
dominante no contexto teórico norte-americano até a década de 60. O utilitarismo alcançou significante proeminência com os escritos de Jeremy Bentham e, posteriormente, de seus seguidores tais como James Mill, James Stuart Mill e Henry Sigdwick.

A análise econômica do Direito (Law and Economics) é uma reação também ao entendimento predominante no ambiente jurídico norte-americano de que o direito deve ser entendido como uma realidade e disciplina autônoma. A construção do entendimento de que o direito possui uma realidade autônoma do ponto de vista metodológico e epistemológico é atribuída a Langdell ${ }^{2}$.

O método do caso (case method ou mechanichal jurisprudence) elaborado por Langdell foi apresentado pela primeira vez na obra Cases on the Law of Contract, em 1871. Esse método irá entender o direito como um conjunto de princípios, conceitos e doutrinas decorrentes da multidão de decisões judiciais, permitindo determinar a aplicação normativa por meio do uso de raciocínios lógicos e da argumentação analógica ${ }^{3}$.

A análise econômica do Direito (Law and Economics) possui como características: i) a rejeição da autonomia do Direito perante a realidade social e econômica; ii) utilização de métodos de outras áreas do conhecimento, tais com economia e filosofia; iii) crítica à interpretação jurídica como interpretação conforme precedentes ou o direito, sem referência ao contexto econômico e social.

O estudo da análise econômica do Direito Tributário deve partir de algumas premissas importantes, para que seja realizada uma análise com a exata proporção da utilidade e métodos que podem ser empregados para o conhecimento do fenômeno tributário. Para tanto, devemos proceder a algumas diferenças metodológicas importantes. É um erro que pode ser encontrado em alguns escritos transmitir a impressão de que a "análise econômica do direito" seja uma escola ou um corpus teórico unificado, sem distinções gigantescas entre autores diferentes. Esse erro é particularmente grave na medida em que impede a exata compreensão da aplicação da análise econômica ao fenômeno jurídico.

A “análise econômica do direito" é mais um movimento do que uma escola única, abrangendo diversas escolas, muitas divergentes entre si, tais como: Escola de Chicago (Chicago Law and Economics), Escola das Escolhas Públicas (Public Choice Theory), Escola da Nova Economia Institucionalista (Institutional Law and Economics).

\subsection{Metodologia}

Esta tem sido entendida, de modo geral, como sendo: a utilização da teoria econômica e métodos econométricos para o exame do Direito e instituições jurídicas.

Apesar de seus resquícios poderem ser encontrados já em Adam Smith, no iluminismo escocês, entre outros, entende-se que ela se desenvolve particularmente nos EUA com os estudos realizados na Universidade de Chicago, especialmente a

${ }^{2}$ Christopher Columbus Langdell (1826 - 1906) foi professor da na Harvard University. Tornou-se famoso pela introdução do método do caso (case method) e dentre suas principais obras se destacam: Selection of Cases on the Law of Contracts (1871); Cases on Sales (1872); Summary of Equity Pleading (1877); Cases in Equity Pleading (1883) e Brief Survey of Equity Jurisdiction (1905).

${ }^{3}$ Cf. Alejandro Bugallo Alvarez. Análise econômica do direito: contribuições e desmistificações. Revista Direito, Estado e Sociedade. nº 29, jul./dez. 2006, p. 49-68. 
partir de 1940 (Coase, Stigler, Posner, entre outros). A primeira obra considerada pioneira dos estudos de análise econômica do Direito é atribuída à Ronald H Coase (The Problem of Social Cost), publicada no Journal of Law and Economics, em 1960. Em seguida é publicada a obra original de Guido Calabresi sobre a distribuição do risco como critério de imputação da responsabilidade, na prestigiada Yale Law Journal, em 1961, sob o título "Some Thougts on Risk Distribution and the Law of Torts". Em 1973 surge a obra Economic Analisys of Law de Richard Posner, que estabelece nova dimensão aos estudos sobre Direito e Economia ao ser o primeiro estudo sistemático sobre a maioria dos setores jurídicos sob a ótica econômica, abrangendo o estudo dos contratos, da propriedade, responsabilidade civil e a atualidade do debate existente na época nos EUA e, particularmente, na Universidade de Chicago 4 .

A complexidade e o desenvolvimento da análise econômica do Direito é bastante significativa, de modo sintético poder-se-ia dizer que existem duas formas básicas de análise: descritiva e normativa. Dito de outro modo, se tratam de duas abordagens distintas a fundamentação do Direito pela Economia ou a verificação da função exercida pelas instituições jurídicas.

A análise econômica do Direito em sentido descritivo trata da aplicação de conceitos e métodos não-jurídicos no sentido de entender a função do Direito e das instituições jurídicas. Tais como: a aplicação da teoria dos jogos ou da teoria das escolhas públicas (public choice).

Há, por outro lado, a análise econômica do Direito que pretende não apenas descrever o Direito com conceitos econômicos, mas encontrar elementos econômicos que participam da 'regra de formação' da teoria jurídica. Desse modo, os fundamentos da eficácia jurídica e mesmo da validade do sistema jurídico deveriam ser analisadas tomando em consideração valores econômicos, tais como a eficiência, entre outros.

Estas duas escolas são denominadas de concepção positiva (positive) e normativa (normative) do direito e economia. A teoria positiva tenta explicar o direito, sua eficácia e como as normas jurídicas podem ser consideradas como sendo eficientes. A teoria normativa, por outro lado, tenta determinar o que deve-ser do direito a partir da análise da realidade. Assim, para Coase se uma determinada conduta econômica, por exemplo a coletivização da agricultura provocar uma fome em massa na sociedade não haverá dúvidas para o economista afirmar que esta decisão econômica não é desejável ${ }^{5}$.

A opinião de que a explicação do direito pela economia não possa ter uma perspectiva normativa é falha, visto que sempre qualquer descrição parte de postulados norteados por valores e juízos de valor. Assim, quando se analisa determinada instituição econômica a própria definição do que venha ser eficiente leva em consideração juízos de valor. Um caso particularmente importante ocorre nos estudos sobre a distribuição de recursos em uma sociedade (just distribution of welfare).

${ }^{4}$ Cf. Alejandro Bugallo Alvarez. Análise econômica do direito: contribuições e desmistificações. Revista Direito, Estado e Sociedade. n $^{\circ}$ 29, jul./dez. 2006, p. 52.

${ }^{5}$ Cf. Coase, Ronald H. Essays on Economics and Economists, Chicago: University of Chicago Press, 1994. 
De modo geral são postulados da análise econômica do Direito:

a) o individualismo metodológico, ou seja, os fenômenos coletivos devem ser explicados como resultantes de decisões individuais;

b) escolha racional, ou seja, as decisões individuais são entendidas como racionalmente dirigidas à maximização dos interesses individuais (benefits over costs);

c) preferências estáveis, postula-se que no curto prazo há a estabilidade de preferências;

d) equilibrium, entende-se que as interações na política e no direito tendem, tal como no mercado ao equilíbrio.

O exemplo mais marcante da fundamentação econômica do Direito encontra-se com Posner no entendimento do valor eficiência como a verdadeira medida do Direito, chegando a afirmar que se você nomear uma instituição legal ele poderia demonstrar como poucos princípios fundamentais da teoria dos preços dita a sua estrutura econômica.

\subsection{Crítica da análise econômica do Direito}

Diversas críticas foram dirigidas à esta teoria (não-falseabilidade dos pressupostos, circularidade, subjetividade dos valores), bem como o reducionismo da tese do Homo Economicus ou mesmo da tese da racionalidade econômica.

No meu entender, os sistemas sociais são formados por subsistemas (político, econômico e jurídico), os quais se influenciam mutuamente, mas que possuem autonomia entre si.

Dessa forma, a previsibilidade e segurança decorrentes de contratos e da propriedade desempenham não são apenas um reflexo do mercado, mas podem ser em certos casos elementos que criam um 'ambiente institucional' favorável a determinado processo econômico.

A 'Análise Econômica do Direito' (Law and Economics), portanto, deve ser considerada como uma abordagem e não como uma teoria. Realmente trata-se de uma distinção bem importante entre escolas de pensamento e abordagens ou movimentos. As escolas apresentam de modo geral um conjunto de postulados compartilhados e defendidos por um grupo de pensadores (escola austríaca, institucionalista, etc). Por sua vez as abordagens ou movimentos apresentam um grau mais difuso de postulados comuns ou heterogeneidade na sua agenda de pesquisa.

\section{ANÁLISE ECONÔMICA DA TRIBUTAÇÃO}

O estudo econômico da tributação possui uma longa história onde podemos citar os estudos de David Ricardo sobre o déficit público (1817); de Cournot (1838) sobre a incidência da tributação nos mercados imperfeitos; de Edgeworth (1925) sobre os efeitos da tributação nas firmas e em Pareto (1909) nos fundamentos das decisões sociais.

É praticamente certo em termos econômicos que nenhuma economia pode operar sem a existência de uma base mínima de organização institucional e que, por sua vez, esta base requer ser financiada (“...laws cannot be policed free of costs") . Portanto, desse fato duas ordens de preocupações têm sido desenvolvidas na teoria econômica: equidade e eficiência. 
De um lado, o Estado deve implementar suas políticas com o mínimo de efeitos para a sociedade ("minimum loss to society"). Minimizar seus efeitos é uma das exigências da eficiência econômica. Por outro lado, o Estado deve agir para obter a mais equitativa distribuição de bens na sociedade, especialmente, perante o fato de vivermos em uma sociedade em que o mercado é imperfeito e existem motivações decorrentes de vontade de promoção de políticas públicas de bem estar social ("welfare-motivated policies"). Este pode se considerado o aspecto da equidade nas políticas de finanças públicas.

O mercado apresenta, de modo geral, duas grandes falhas: i) bens públicos exclusivos (não rivais), visto que um agente pode consumir sem reduzir o consumo de outros agentes e ii) presença de efeitos externos ("presence of external effects"), dado que o mercado não pode alcançar sozinho o seu nível ótimo. Dessa forma, "tributos corretivos" ("corrective taxes”) são formas de corrigir falhas de mercado ("market failure"). Mesmo Adam Smith considerava que os tributos são "preços” a serem pagos para o fornecimento de três categorias de bens públicos para seus súditos: defesa, justiça e bens públicos sujeitos a externalidades (p.ex.: educação primária).

\subsection{Teorema de Coase: a tributação como custo de transação}

Uma das mais importantes teses criadas na teoria econômica recebeu a denominação de Teorema de Coase, em homenagem ao economista norte-americano Ronald Coase ${ }^{6}$. Esta teoria se consagrou em função de suas inúmeras aplicações e pela reafirmação em diversos trabalhos e por estabelecer os primórdios da análise sobre a estrutura institucional onde o mercado se desenvolve. A ideia foi originalmente concebida em um paper publicado em 1937, sob o título de "A natureza da firma" ('The Nature of the Firm ") em que o autor definia que a natureza da firma deve ser considerada simplesmente como sendo o custo de utilização do mecanismo de mercado ('The Nature of the Firm as simply 'the cost of using the price mechanism'). Em virtude de sua relevância iremos apresentar algumas de suas teses mais originais.

\subsection{Os custos de transação}

Afirma Coase que a teoria neoclássica sobre os custos de transação se sustentava exclusivamente na noção de custos de negociar em mercado, enquanto que os direitos de propriedade sustentam-se nos custos de estabelecer e proteger os direitos de propriedade ("the 'property rights' definition centers on the costs of establishing and enforcing property rights").

Coase demonstrou que as análises tradicionais sobre a teoria microeconômica eram incompletas, visto que unicamente incluíam os custos de produção e transporte e negligenciavam os custos de celebração e execução de um contrato, bem como de administrar uma firma. Segundo o autor estes custos podem ser denominados de custos de transação, visto que representam uma parte considerável dos recursos utilizados de uma sociedade para manter o mecanismo social de trocas e negociação.

${ }^{6}$ O Prof. Ronald Coase foi premiado com o Prêmio Nobel em Economia em 1991 (Alfred Nobel Memorial Prize). Atualmente é professor na Universidade de Chicago (Chicago Law School) desde 1961. Foi editor do Journal of Law and Economics (1964-1982) e é presidente do International Society for New Institutional Economics (1996-97). ${ }^{7}$ Coase, Ronald. The nature of the firm. Economica, New Series, Vol. 4, no 16 (November 1937), pp. 386-405. 
Seu pioneirismo está em levar em conta os motivos que fazem o mercado criar firmas, estabelecer diferentes formas societárias, criar tipos contratuais diversos, montar uma estrutura determinada no sistema financeiro e mesmo regulamentar instituições jurídicas diferentes. A explicação para fenômenos tão diversos quanto estes podem ser encontrados em uma explicação simples: na existência de custos de transação. Estes podem explicar o porquê as pessoas criam arranjos contratuais ou mesmo firmas, como forma de reduzir os custos de transação.

Os contratos ou as firmas significam meios de redução de complexidade, incerteza e imprevisibilidade, dotando os agentes econômicos de signos de programação de condutas intertemporais, evitando o custo em parar a produção ou a circulação com discussões e decisões sobre fatos já acordados. Assim, ao invés das partes viverem em clima de negociação o contrato pretende trazer respostas para possíveis perguntas, dúvidas ou divergências sobre temas tão distintos quanto: a rescisão, o pagamento, o objeto contratual, multas, pagamentos, entre tantos outros temas que o contrato pode prever.

As firmas, por sua vez, são estruturas de organização da produção que diminuem a existência de negociações permanentes na linha de montagem, entre o operário de uma ponta e outro, ou entre o empregador e empregados.

A literatura definia os custos de transação de modo restritivo ao identificá-los, especialmente, com tarifas de transporte e tributos. Outros tipos de custos ainda podiam ser citados, tais como: custos sobre o volume de transação, competência em arbitragem, intermediação e existência de equilíbrio no sentido neoclássico.

Posteriormente, a publicação da obra de Coase denominada de "O problema dos custos sociais" ("The Problem of Social Cost") foi escrita com a aplicação de muitas ideias elaboradas anteriormente e estabeleceram as bases da futura agenda sobre os direitos de propriedade.

O grande questionamento apresentado nesta obra decorre da pergunta sobre porque era necessária uma teoria para explicar os custos de transação se o mecanismo de preços determinam toda a coordenação necessária em uma economia de mercado. A pergunta inicial era bastante simples: por que ao invés de utilizar mecanismos de mercado as firmas utilizavam no seu interior mecanismos de hierarquia, ou seja, de comando e controle nas suas relações internas ${ }^{9}$. Assim, se o mercado é o grande mecanismo de alocação de recursos, por que não é utilizado no interior da firma? Por que um trabalhador da linha de montagem não negocia com o trabalhador ao seu lado, que cobrará pelo produto parcialmente acabado? Por que afinal prevalece a negociação e a contração e não a hierarquia?

A resposta dada por Coase era a de que a estes são custos sobre o uso de mecanismo de preços ('costs of using the price mechanism') ${ }^{10}$. Quando os preços são

\footnotetext{
${ }^{8}$ Cf. Coase, Ronald. The Problem of Social Cost. Journal of Law and Economics Vol. 3 (October 1960), pp. 1-44.

${ }^{9}$ Segundo Coase: "but in view of the fact that it is usually argued that co-ordination will be done by the price mechanism, why such organization necessary?”; ver in Coase, The nature..., op. cit., p. 388. Ou ainda: "yet, having regard to the fact that if production is regulated by price movements, production could be carried on without any organisation at all, well might we ask, why is there any organization?; Coase, idem ibidem. ${ }^{10} \mathrm{Cf}$. Coase: ,the main reason why it is profitable to establlish a firm would seem to be that there is a cost of using the price mechanism"; ver in Coase, The nature of...., op. Cit., p. 390. Em outra obra significativa sobre o
} 
alocados a determinado custo eles competem com outros mecanismos, tais como firmas e governos, assim conforme Coase em determinadas situações, firmas e administração direta superam o mercado e em outras situações o mecanismo de preços são usados em prover bens e serviços.

Dessa forma, a sua resposta era bastante provocativa: tudo depende dos custos para a realização de transações. Aquelas atividades coordenadas por meio de relações de comando e controle que possuírem um custo de transação menor que as relações de negociação de preços (mercados) para alcançarem determinadas metas irão se sobrepor como soluções escolhidas.

A pergunta seguinte é: quais os custos relevantes de transação? Para Coase existem três categorias gerais: custos de informação e procura ${ }^{11}$, custos de decisão e barganha $^{12}$ e custos de controle e execução ${ }^{13}$.

A teoria dos custos de transação tem com pressupostos teóricos a ideia de racionalidade limitada, complexidade e incerteza, oportunismo e especificidade de ativos. A teoria parte do pressuposto de que os agentes econômicos são racionais, porém não detém todos os elementos para uma decisão racional. Não há como um agente prever todas as contingências futuras decorrentes de um contrato. Outro pressuposto é que não há como o mercado evitar a presença de comportamentos anti-éticos em uma negociação, o que foi denominado de oportunismo ${ }^{14}$.

Os ativos específicos são, por outro lado, aqueles que são reempregáveis somente com uma perda de valor a cada utilização, o que gera um custo adicional de transação. Podendo ser definido, por outro lado, como sendo aquele ativo que produzirá uma perda para o agente se for realizada uma utilização diversa para o mesmo. Como por exemplo, podemos citar os ativos de local, nos quais temos como exemplos os móveis e infra-estrutura, que são difícil realocação para outros usos ${ }^{15}$.

A abordagem de Coase produziu uma revolução no pensamento econômico, questionando pressupostos arraigados da teoria econômica ortodoxa, que entendia

tema questiona Coase que: „why does the firm assumethe by]urden of the costs of establishing and running this administrative structure, when the allocation of resources coud be left to the pricing system?; ver in Coase, R. Industrial Organization: a proposal for research. In Victor R. Fuchs (ed.) Policy issues and research opportunities in Industrial Organization. New York: National Bureau of Economic Research, 1972, p. 59-73.

${ }^{11}$ Cf. Coase: ,the most obvious cost or ,organising' production through the price mechanism ist that of discovering what the relevant prices are"; ver in Coase, The nature of...., op. Cit., p. 390.

${ }^{12}$ Cf. Coase: „The costs of negotiating and concluding a separate contract for each exchage transaction which takes place on a market must also be taken into account"; ver in Coase, The nature of...., op. Cit., p. 390-391.

${ }^{13}$ Cf. Kupfer, David. Economia Industrial: Fundamentos teóricos e práticos no Brasil. 2. Ed., Rio de Janeiro: Campus, 2002, p. 269.

${ }^{14}$ Cf. FARINA, Elizabeth Maria Querido. Competitividade: mercado, Estado e organizações. São Paulo: Singular, 1997, p. 71 e 72.

${ }^{15}$ Conforme Williamson a especificidade dos ativos pode ser de seis tipos: $i$ ) especificidade de ativos de local (ex.: imóveis e infraestrutura); ii) de ativos físicos ( ex.: máquinas e equipamentos que geram interdependência); iii) de ativos humanos (ex.: capacitação por meio de cursos e treinamento); iv) de ativos dedicados (ex.: investimentos que estão direcionados a um cliente específico); v) ativos relacionados à marca e vi) ativos temporais (ex.: aqueles em que não é fácil separar fatores tecnológicos de uma transação ou na perecidade dos produtos alimentares). In Williamson, (1996, p. ). 
que a racionalidade econômica no mercado era ilimitada e completa. Conforme demonstrou o autor, os agentes ao contratarem possuem informações limitadas sobre os efeitos futuros da contratação, bem como uma assimetria de informações. Essa assimetria se refere a situação na qual comprador e vendedor possuem informações diferentes sobre uma transação. Nesse caso, uma das partes está privilegiada perante a outra. Pense em alguém que irá contratar um mecânico para resolver um problema em um carro, geralmente este possui informações que não estão disponíveis para o comprador, que somente terá duas saídas confiar ou buscar outro profissional. O mesmo modelo pode ser aplicado para os serviços prestados por médicos, advogados, corretores de ações, entre outros.

A teoria dos custos de transação foi adotada por diversos autores, dentre os quais podemos destacar Oliver Willianson ${ }^{16}$ e Douglass North ${ }^{17}$.

A tributação pode, neste sentido, ser entendida tanto como um custo de transação em sentido restrito, quanto em sentido amplo. Sendo que em ambas as situações a tributação possuirá um papel relevante na determinação da realização do negocio jurídico, influenciando decisivamente as escolhas dos agentes econômicos.

\subsection{A tributação e os custos de transação}

Os estudos sobre a aplicação da teoria dos custos de transação em relação ao problema da tributação são ainda incipientes e, em verdade, inexistem grandes obras sobre o assunto, contudo, se pode vislumbrar um conjunto de aplicações onde esta teoria poderia ser muito útil.

A tributação pode ser entendida como sendo um custo de transação em sentido restrito, na medida em que se constitui em um custo para a formalização de um negócio jurídico, assim em uma operação em que a mercadoria custa 1000 e o imposto incidente sobre a operação de circulação e 10\%, o custo adicional para a realização do negócio e 100, totalizando 1100.

De outra parte, a tributação pode ser entendida também como sendo um custo de transação em sentido amplo, ou seja, conforme o teorema de Coase. Nesse caso, a tributação pode ser verificada como um custo a ser verificado na utilização dos mecanismos de mercado. As inseguranças decorrentes de um sistema tributário imperfeito e ineficiente implicam em uma maior incerteza na contratação e, portanto, em um custo de transação maior.

Segundo Coase: "um outro fator que deve ser levado em consideração é o fato de que as operações de troca em uma economia de mercado e mesmo transações organizadas dentro de uma mesma firma são freqüentemente tratadas diferentemente

${ }^{16}$ O Prof. Oliver Williamson é professor na Universidade Berkeley e entre outras obras podemos citar "Transaction Cost Economics: governance of contractual relations". Journal of Law and Economics, $n^{\circ} 22$, october 1979, p. 233-261 e "The economic Institutions of Capitalism: firms, markets, relational contracting". New York: Free Press, 1985.

${ }^{17}$ O Prof. Douglass North é autor de diversas obras sobre teoria econômica, especialmente Institutions, Institucional Change and Economic Performance e Understanding the Process of Economic Change. O autor recebeu o Prêmio Nobel em 1963. Seu principais estudos se referem a ciência cognitiva e o impacto de decisões sociais no desenvolvimento econômico de longo prazo. 
pelo Governo ou outros organismos ou agências regulatórias"18. Um exemplo citado pelo autor se refere à cobrança do imposto sobre as vendas (sales tax), que pode significar inclusive um fator determinante no tamanho das firmas em uma economia de mercado, visto que as empresas podem concentrar operações internas para evitar a incidência desta tributação ${ }^{19}$.

Igualmente, a tributação possui uma influência fundamental na escolha dos arranjos contratuais ${ }^{20}$.

Imagine-se, por exemplo, um empresário que venha a realizar a importação de um equipamento para a produção industrial, se ele não puder mensurar o custo tributário dessa operação, ou para utilização do mecanismo de mercado será significativo.

A tributação deve ser tratada como sendo um custo de transação (custo de utilização dos mecanismos de mercado) nas seguintes situações: $i$ ) insegurança jurídica; ii) sonegação; iii) burocracia fiscal, iv) incentivos fiscais e iv) elevadas penalidades em matéria tributária. Desse modo, um agente de mercado pensará duas ou mais vezes antes de estabelecer uma empresa formal se os custos de transação forem superiores a atuação mediante uma empresa informal.

Como se pode vislumbrar, é possível encontrar um conjunto vigoroso de situações onde a aplicação do conceito de custos de transação pode representar um importante instrumento de análise.

3.4. A Nova Economia Institucional (New Institutional Economics): tributação como instituição

A denominação Nova Economia Institucional (NEI) foi cunhada por Oliver Williamson para denotar o esforço de autores como Ronald Coase, Oliver Williamson e Douglass North em tratar o fenômeno econômico ligado aos seus aspectos políticos e sociais, com especial ênfase no papel das instituições. Esta escola possui ainda como antecessores os trabalhos de to Coase (1937), Hayek (1937), Chandler (1962), Arrow (1963), North (1971), Williamson (1971) e Holmström (1979).

\subsection{Contribuições da Nova Economia Institucional (New Institutional} Economics)

A NEI parte de duas constatações: primeiro, “as instituições importam” (institutions do matter) e, segundo, as "instituições são suscetíveis de análise econômica" (the determinants of institutions are susceptible to analysisby the tools of economic theory) ${ }^{21}$.

${ }^{18}$ Assim: another factor that should be noted is that exchange transactions on a market and the same transations organised within a firm are often treated differently by Government or other bodies with regulatory power.“; ver in Coase, The nature of..., p. 393.

19 Desse modo: „If we consider the operation of a sales tax, it is clear that it is a tax on market transactions and not on the same transactions organised within the firm “ $e$ „(...) of course, to the extent that firmsalready exist, such a measure as a sales tax would merely tend to make them larger than they would otherwise be"; ver in Coase, The nature of..., op. cit., p. 393.

${ }^{20}$ Segundo Coase: "there is other evidence that I thought about the firm in terms of a choice of contractual arrangements"; ver in Coase, Ronald. The nature of the firm: meaning in Williamson, Oliver E. Et Winter, Sidney G. The nature of the Firm - Origins, Evolution, and Development. New York/Oxford: Oxford University Press, 1993, p. 56.

${ }^{21}$ Cf. Williamson, Oliver E. The New Institutional Economics: Taking Stock, Looking Ahead. Journal of Economic Literature, Vol. XXXVIII (September 2000) pp. 595-613. 
Estas duas considerações representam uma ruptura com o modelo de pensamento neoclássico sobre o Estado, visto que para esta escola o Estado é entendido sob a forma de contrato ou de ordem violenta. Na teoria contratual do Estado as instituições são um terceiro perante os indivíduos, possibilitando que as trocas entre estes ocorram sob um ambiente favorável. Na teoria do Estado como ordem violenta este é uma das partes em uma sociedade divida por uma distribuição desigual de recursos.

Apesar de representar o esforço de autores tão diversos como estes a NEI apresenta alguns postulados comuns, tais como: i) uso do individualismo metodológico para explicar fenômenos econômicos e sociais; ii) foco na explicação da ação coletiva; iii) preferência por um enfoque evolucionário (evolutionary) do que mecaniscista (mechanistic approach to the economy) e iv) enfâsis na observação empírica, em oposição ao método dedutivo.

Uma distinção relevante apresentada por North e Davis está na distinção entre "ambiente institucional" (institutional environment) e "arranjos institucionais" (institutional arrangements). O primeiro termo designa as regras do jogo que orientam o comportamento individual (rules of the game) e podem ser tanto explícitas e formais (constituição, leis e códigos), como serem regras implícitas e informais (convenções sociais e regras morais).

Os "arranjos institucionais" (institutional arrangements), por outro lado, se dirigem aos objetivos e escolhas realizadas pelos atores individuais de modo específico para determinar relações econômicas específicas (governance structures), tais como contratos, firmas, empresas, organizações burocráticas e sem fins lucrativos.

Os “arranjos institucionais” (institutional arrangements) possui as seguintes características: i) reduz incertezas ao estruturar a interação entre indivíduos ("institutions reduce uncertainty by providing a structure to everyday life"22) e ii) surgem espontaneamente e não previamente como em uma partida esportiva. Estes arranjos são formas encontradas pelos agentes sociais em coordenar seus interesses e escolhas e aparecem de modo muito claro nas convenções sociais e regras de conduta. As convenções sociais são entendidas como uma espécie de jogos não-cooperativos (noncooperative Nash-equilibrium solutions). Um jogo não-cooperativo é aquele que os participantes não realizam compromissos mútuos, por sua vez o uso do modelo de Nash (Nash-programme) é utilizado para demonstrar que muitas das soluções cooperativas são em verdade resultados do chamado equilíbrio de Nash (noncooperative equilibria). Este modelo é designado em homenagem ao seu propontente John Forbes Nash como solução para um jogo envolvendo dois ou mais jogadores em que nenhum tem nada a ganhar mudando unilateralmente a sua estratégia. Se nenhum jogador alterar suas posições mantendo os resultados decorrentes de suas estratégias teremos o denominado equilíbrio de Nash.

Um exemplo sugerido ${ }^{23}$ por Thomas Schelling ${ }^{24}$ é o de dois amigos que combinam

${ }^{22}$ Cf. North (1990, p. 3).

${ }^{23}$ Cf. Schelling, Thomas C. (1960), The Strategy of Conflict, Cambridge, MA, Harvard University Press.

${ }^{24}$ Thomas Crombie Schelling (1921) é um dos mais importantes economistas norte-americanos e professor na School of Public Policy at University of Maryland College Park. Foi ganhador do prêmio Nobel em 
de se encontrar determinado dia às 05:00 da manhã, contudo, como o passar do tempo acabam se esquecendo do lugar combinado e passam a cogitar o ponto de encontro independentemente um do outro. Se por acaso escolhessem qualquer lugar coincidente, por exemplo, na 34th Street e 5th Avenue, seria considerado um equilibrio de Nash, dentre as infinitas possibilidades. Existem, contudo, padrões culturais firmados tais como a crença comum de que os encontros se realizam "logicamente" em New York sob o relógio da Grand Central Station. Este ponto seria denominado de "ponto focal“ (focal point), para denominar as regularidades comportamentais utilizadas para resolver problemas de coordenação. Uma instituição social (social institution) poderia ser entendida como sendo uma espécie de regularidade social.

Outro ponto significativo está no entendimento de como as economias se desenvolveram durante os séculos (economic growth), entendendo-se o desenvolvimento como uma forma de resposta evolutiva para os desafios surgidos no campo social e econômico. Como exemplos, podemos citar a padronização de medidas (metragem e peso) no início da era moderna com uma forma de redução dos custos de informação e o florescimento de mercados em cidades que evitavam expropriar a riqueza.

Igualmente relevante tem sido o entendimento de North de que as ideologias, ao lado das instituições, se constituem em formas bem sucedidas de se lidar com a complexidade nas decisões em um ambiente de incerteza. Enquanto as ideologias seriam aparatos internos de ordenação da complexidade, as instituições seriam modelos externos. Por outro lado, North irá destacar o papel das ideologias na manutenção da estabilidade institucional e do consensus ${ }^{25}$.

O modelo neoclássico de Estado previa um dilema insuperável na medida em que estabelecia dois postulados contraditórios: i) comportamento individual tendente à maximização da riqueza (wealth maximization) e ii) modelo hobbesiano de Estado de limitação da liberdade individual. Na medida em que os indivíduos agem para potencializar a primeira formulação irão irracionalmente tender para descumprir as limitações estabelecidas no segundo postulado e, por outro lado, a decisão de desafiar os limites do Estado estaria sujeita tão somente a considerações de custo e benefício, então os custos de manutenção da ordem se tornariam exponencialmente caros para a manutenção de qualquer ordem social.

Para North os comportamentos individuais assentam-se em grande parte no chamado problema do carona (free rider problem $^{26}$ ), ou seja, as condutas oportunísticas realizadas pelos indivíduos que auferem ganhos privados da ação dos outros, assim, por exemplo, o ato do fura greve que não se arrisca na greve mas torce pelo seu sucesso é tipicamente uma conduta de carona. Parte o autor do entendimento de que

2005 Nobel Prize, juntamente com Robert Aumann, por seus estudos fundamentais sobre o entendimento do conflito com utilização do instrumental fornecido pela teoria dos jogos (game-theory analysis). É autor, dentre inúmeras outras, das seguintes publicações: The Strategy of Conflict (1960); Strategy and Arms Control, com Morton H. Halperin (1961); Micromotives and Macrobehavior (1978) e Choice and Consequence (1984).

${ }^{25}$ Cf. North, Douglass. Structure and change in economic history. New York/London: Norton \& Company, 1981, p. 45 e segs.

${ }^{26}$ O chamado problema do carona (free rider problem) é atribuído à Mancur Olson, em sua obra The Logic of Collective Action: Public Goods and the Theory of Groups (1965). 
as pessoas continuam realizando condutas que não trazem ganhos diretos ou mensuráveis em um comportamento de cálculo diário sobre custos e benefícios de modo automático. Se não fosse assim algumas condutas não poderiam ser explicadas, tais como o fato de que as pessoas continuam doando sangue ou votando. Grande parte das condutas estão fundadas em valores inculcados pela família e pela sociedade e, portanto, o fato de não tomar ações oportunísticas de "carona" devem-se mais ao fato de minha ideologia do que de um cálculo de oportunidades. Assim, o funcionário poderá continuar sendo diligente mesmo sabendo que se fosse preguiçoso e o seu serviço fosse feito por outro a resultante final de trabalho seria a mesma, contudo, não o faz por razões íntimas distantes de um cálculo de benefícios diretos.

3.6. Contribuições da Nova Economia Institucional (New Institutional Economics) para a compreensão do fenômeno da tributação

O estudo da importância institucional dos tributos em uma sociedade democrática tem seu maior representante em Casalta Nabais, através de sua obra monumental: “O Dever Fundamental de Pagar Tributos". O tema dos deveres fundamentais encontrou-se esvaziado de interesse pelos juristas após a trágica experiência histórica das democracias ocidentais sob horrores do totalitarismo fascista, nazista e stalinista, o que forjou uma aversão a qualquer possibilidade de determinação absoluta do poder perante a liberdade individual. Dessa forma, os textos constitucionais preocuparam-se especialmente na afirmação dos direitos fundamentais, evitando qualquer brecha a uma interpretação constitucional que permita o surgimento de regimes antidemocráticos.

Para Casalta Nabais os deveres fundamentais devem ser entendidos como uma categoria jurídica autônoma ao lado dos direitos fundamentais. Dessa forma, seriam evitados dois equívocos: de um lado a diluição dos deveres no conceito de soberania e de outro se esvaziamento pela submissão aos direitos fundamentais. Para o autor este conceito deve ser entendido de modo autônomo, ou seja, como portadora de valores constitucionais e "comunitários diferentes e contrapostos aos valores $e$ interesses individuais consubstanciados na figura dos direitos fundamentais”.

Para o autor, isso não impede, contudo, por mais paradoxal que seja, como bem alerta, que estes deveres sejam considerados como integrantes dos direitos fundamentais. Essa designação se dirige tanto para os deveres fundamentais que são considerados limites específicos ou gerais para os direitos fundamentais.

Temos assim uma dupla dimensão dos deveres fundamentais, tal como para os direitos fundamentais. A dimensão subjetiva dirige-se ao indivíduo e à atribuição de uma posição passiva, enquanto que a dimensão objetiva determina que os custos e encargos para o financiamento dos direitos fundamentais sejam suportados por todos. Em uma sociedade democrática a dimensão subjetiva possui maior peso que a dimensão objetiva, visto que se deve considerar particularmente a prevalência da liberdade sobre o poder e a ordem. A autoridade recebe autorização nos limites de uma ordem fundada na liberdade.

Desse modo, outra característica decorre do sistema de deveres fundamentais, aquela que exige que exista uma interpositio legislatoris que os concretize e os torne aplicáveis pela Autoridade. O entendimento da importância institucional dos deveres fundamentais como forma de financiamento dos direitos fundamentais é um dos 
elementos mais destacados deste novo enfoque, bem como da compreensão de como os custos de transação podem influenciar a eficiência econômica e a geração de prosperidade para uma nação. A tributação deve ser enxergada, portanto, como uma peça chave na realização geral de eficiência do sistema e como mecanismo promoção de instituições que promovam o desenvolvimento e não que transfiram recursos para uma classe política ou econômica privilegiada.

Por fim, uma última contribuição que poderia ser mais bem explorada está na aplicação do problema do carona (free rider problem) para explicar diversos fenômenos oportunísticos em tributação, tais como: sonegação, planejamento tributário, inadimplência fiscal, uso e abuso de incentivos fiscais, guerra fiscal, dentre tantos outros.

\section{O PROBLEMA DA EFICIÊNCIA}

A eficiência econômica irá possuir o sentido de maximização de determinados bens sociais eleitos como sendo de significativa importância. Como podemos notar não se trata de um conceito neutro ou ausente de compreensões ou pré-compreensões, visto que a determinação de determinado objetivo a ser maximizado expõe uma visão de mundo. Será fundamental a definição da "unidade de medida" (measuring rod, sendo que rod significa em inglês bastão ou vara) do critério de eficiência. Estes dois critérios tentam responder ao questionamento: se as pessoas maximizam o que elas maximizam mesmo? (If people maximize, what do they maximize?) ${ }^{27}$. Os bens a serem escolhidos são: i) utilidade (utility), ii) dinheiro (money) iii) "riqueza humana" e a iv) felicidade (happiness).

O uso destes critérios tem por objetivo a determinação da maximização da riqueza considerada como o conjunto de bens desejáveis, ou seja, coisas que satisfazem direta ou indiretamente necessidades ou desejos humanos ${ }^{28}$. Em virtude da multiplicidade de necessidades e desejos humanos é necessário encontrar um critério de conduta capaz de mensurar as diversas escolhas individuais e sociais. Este critério deve ser o mais amplo e genérico possível para abarcar a maior diversidade de bens.

O uso da utilidade como critério permite a abstração das preferências individuais e a possibilidade de uma mensuração sobre a importância de determinado bem e comparação com outros. Assim, mais determinado item é específico mais ele tem utilidade para determinado indivíduo. Outra vantagem do uso da utilidade está no fato que ele pode dirigir-se a questões tão diversas como dinheiro, tempo, o cumprimento de regras e mesmo o amor ${ }^{29}$.

Outro critério utilizado é o dinheiro, mas com a desvantagem perante a utilidade como critério de medida na medida em que para o dinheiro o acréscimo de uma unidade

\footnotetext{
${ }^{27}$ Cf. Kerkmeester, Heico. Methodology: General In De Geest, G. et Bouckaert, B. Encyclopedia Of Law And Economics, Volumes I-V. Publicação online disponível em http://encyclo.findlaw.com. Acesso em 6 ago. 2007 às 14 h. p. 386.

${ }^{28}$ Cf. Marshal, Alfred. Princípios de Economia, vol. 01. Col. Os Economistas. São Paulo: Abril Cultural, 1982, p. 65.

${ }^{29}$ Cf. Kerkmeester, Heico. Methodology: General In De Geest, G. et Bouckaert, B. Encyclopedia Of Law and Economics, Volumes I-V. Publicação online disponível em http://encyclo.findlaw.com. Acesso em 6 ago. 2007 às 14 h. p. 386-388.
} 
diminui seu valor ao invés de acrescentar. Assim, se tenho um real e acrescento outro tenho um acréscimo de $50 \%$, para cada real adicional terei uma redução no acréscimo, assim, a próxima unidade irá acrescentar somente 33\% de valor e assim gradativamente. Tal não ocorre com as preferências em que a utilidade do afeto não se diminui com a sua intensidade, maximizar a utilidade somente potencializa a unidade e não o contrário como no dinheiro.

A imprecisão do termo "utilidade" fez com que Ronald Coase comparasse este com o uso do conceito de "éter" na Física antiga. Tratava-se de um conceito não observável e não mensurável, mas era utilizado porque permitia a concepção clássica da física funcionar. Dessa forma as críticas ao manejo do conceito de "utilidade" decorrem dos seguintes elementos:

i) incapacidade de mensuração ou não-falseamento, dado que se trata de um conceito subjetivo, o que útil para um não é necessariamente para outro. Para alguns o dinheiro é um fim absoluto, para outros é a espiritualidade, etc;

ii) circularidade do argumento: a "utilidade" é explicada pela observação de comportamento e, portanto, a única forma de previsão é verificando-se o comportamento que já ocorreu. Assim, a "utilidade” torna-se um conceito circular porque ela não realiza previsões, mas confirma o que já ocorreu e explica o que ocorreu pelo recurso a previsões de fatos que ainda não ocorreram...

O dinheiro tem sido apontado com o mais eficiente elemento de alternativa ao conceito de "utilidade" por Coase e Posner. O dinheiro possui as seguintes vantagens perante o conceito de "utilidade": i) comparações interpessoais são mais fáceis de serem realizadas e ii) é intuitivo aceitar que as pessoas preferem ter mais dinheiro do que ter menos. Como elemento adicional Richard Posner defende o conceito de "maximização da riqueza" (wealth maximization) fundado no conceito de disposição em pagar (willingness to pay) que consiste na ideia de que a riqueza será maximizada se os recursos estiverem na propriedade de pessoas que desejarem pagos a maior quantia por eles.

As críticas a uso destes dois elementos têm sido muito fortes por parte de autores renomados como Ronald Dworkin e Martha Nussbaum. Para Martha Hussbaum o comportamento humano é muito complexo para ser apreendido pela mera menção ao critério da utilidade ou monetário. Como lembra Dworkin a disposição de pagar pode esbarrar na impossibilidade de pagar dos mais pobres, gerando indagações sobre a justiça da distribuição de recursos. Por outro lado, pode o conceito de "maximização da riqueza" (wealth maximization) levar a soluções conflitantes com a noção de direitos individuais, visto que um ditador poderia sob o argumento de distribuir renda tomar os bens de A e dá-lo para B sem nenhuma consideração aos direitos individuais. Um conceito mais aproximado da maximização esperada pode ser encontrada na noção de "riqueza humana", ou seja, daquela espécie de riqueza de bens imateriais como as qualidades e faculdades pessoais para sentir prazer, tais como a faculdade em deleitar-se com a leitura ou a música (bens internos) ${ }^{30}$. A grande dificuldade na

${ }^{30}$ Cf. Marshal, Alfred. Princípios de Economia, vol. 01. Col. Os Economistas. São Paulo: Abril Cultural, 1982, p. 65.

DIREITOS FUNDAMENTAIS E JUSTIÇA N 7 -ABR./JUn. 2009 
escolha deste critério está no fato de que a A doutrina não tem encontrado alternativas consensuais ao uso do dinheiro e a "utilidade" como unidade de medida, especialmente pela falta de um elemento que cumpra os requisitos de estabilidade, objetividade e simplicidade.

Como se pode perceber nenhum dos critérios acima apresentados consegue responder de modo integral ao desafio de constitui-se em uma unidade de medida daquilo que se deseja maximizar.

\subsection{O debate entre Dworkin e Posner sobre a justiça e a eficiência}

Dworkin $^{31}$ inicia suas indagações questionando se a eficiência busca a riqueza social considerando a riqueza como um valor em si ou como um instrumento para alcançarem-se outros valores $^{32}$. Trata-se, portanto, de determinar-se se justiça e eficiência são valores independentes e conciliáveis ou fazem parte de um valor mais e, portanto, se deve existir um critério de relação ou mesmo de hierarquia ${ }^{33}$.

Para Posner a tarefa dos juízes é simplesmente estabelecer regras que maximizem o bolo econômico, cabendo ao Executivo e Legislativo as regras sobre gestão e distribuição.

\subsection{As normas jurídicas como instrumento de eficiência econômica}

As instituições e normas jurídicas podem ser entendidas como instrumentos para encorajar ou manter um ambiente de eficiência econômica (law as a tool to encourage economic efficiency). Considerando que os indivíduos agem de modo a maximizar seus recursos e que eles se encontram em um ambiente social de trocas espontâneas, conduzidas por critérios de eficiência, e de transferências compulsórias de recursos, orientados por critérios de justiça (equity) o direito possui um papel significativo no resultado individual e total do conjunto de trocas realizados. As normas jurídicas tanto influenciam o resultado individual quanto coletivo da conciliação de trocas realizadas sob a égide dos ditames de eficiência e justiça (equity).

Como o Direito pode encorajar a eficiência nas transações? O direito realiza esta tarefa por diversos meios, dentre os quais podemos destacar: i) corrigindo ou prevenindo as falhas de mercado (market failure), assim, por exemplo, quando o direito estabelece regras jurídicas que evitam o surgimento de monopólios ou cartéis lesivos à eficiência geral do sistema; ii) garantindo a previsibilidade e a o cumprimento de promessas negociais ou iii) regulando as externalidades, ou seja, os custos que não são diretamente refletidos nos preços de bens e que são transferidos para terceiros de modo involuntário. Um exemplo de externalidade pode ser encontrado nos custos ambientais de produtos poluentes.

${ }^{31}$ Dworkin debate com as ideias de Calabresi e Posner sobre a eficiência e a justiça nas seguintes obras: Taking Rights Seriously (1977); A Matter of Principle (1985); Law's Empire (1986) e Sovereign Virtue: The Theory and Practice of Equality (2000).

${ }^{32}$ Cf. Dworkin, Ronald. Why Efficiency? A Response to Professors Calabresi and Posner. Dworkin, Ronald. Is Wealth a Value? The Journal of Legal Studies, Vol. 9, $\mathrm{n}^{\circ}$ 2, Change in the Common Law: Legal and Economic Perspectives (Mar., 1980), pp. 191-226.

${ }^{33}$ Segundo Dworkin: "É, afinal, uma idéia conhecida em teoria política que a sociedade justa encontrará algum compromisso entre a eficácia e a distribuição”; ver in Dworkin, Ronald. A virtude soberana. A teoria e a prática da igualdade. São Paulo: Martins Fontes, 2005, p. 64. 
Preferimos entender que o direito é um sistema modulador de eficiência $e$ equidade de um determinado sistema social, ou seja, não é apenas um instrumento de eficiência, mas é o próprio instrumento de realização da eficiência e de sua ponderação com as exigências de igualdade e equidade.

\subsection{Eficiência (efficiency) e distribuição de renda (income distribution)}

A economia do bem-estar (welfare economics) possui dois aspectos principais: a eficiência econômica (economic efficiency) e a distribuição de renda (income distribution). A eficiência econômica trata de "aumentar o tamanho do bolo econômico" (size of the pie), enquanto que a distribuição de renda pretende decidir "como dividir o bolo" (dividing up the pie). A eficiência distributive será considerada como a capacidade de distribuir melhor os bens para quem realmente precisa ou, conforme a linguagem econômica, para aqueles que ganham mais utilidade.

Existem duas correntes sobre a economia do bem-estar social: a teoria neoclássica e a nova escola da economia do bem-estar social. A teoria neoclássica é representada por Edgeworth, Sidgwick, Marshall e Pigou e afirma que é possível construir uma determinação do bem-estar social mediante a simples soma das funções individuais de utilidade, ou seja, somando-se o que significa utilidade para cada um dos indivíduos de uma determinada sociedade.

A Nova Escola da Economia do Bem-Estar Social (New Welfare Economics) foi desenvolvida especialmente por Pareto, Hicks e Kaldor. A eficiência econômica e a distribuição de renda são consideradas como problemas distintos e que exigem instrumentos diferentes de análise. Para a eficiência utilize-se como critério os modelos de Pareto e Kaldor-Hicks. Assim, para medir o bem-estar social entender-se que este será eficiente quando a melhoria de posição de um indivíduo (better off) não significar a piora na condição de outro (worse off). Por sua vez, os problemas de distribuição são verificados mediante funções de bem-estar social (welfare function)

A ideia de função de bem-estar social (social welfare function) foi apresentada pela primeira vez em 1938 em um artigo de Abram Bérgson, com o intuito de definir a forma precisa de julgamentos de valor requeridos para a determinação de condições para a maximização do bem estar econômico (maximum economic welfare) ${ }^{34}$. Tratase de um estudo que encontra paralelo nas análises de iniciais de Jeremy Bentham, J.S. Mill, F.Y. Edgeworth, e, posteriormente, A.C. Pigou Lionel Robbins, Abba Lerner, John Hicks, Nicholas Kaldor entre outros.

\subsection{Neutralidade econômica da tributação}

Como foi verificado anteriormente Estado deve implementar suas políticas com o mínimo de efeitos para a sociedade ("minimum loss to society"), bem como a sua influência sobre as decisões econômicas dos agentes privados deve ser realizada de modo a influenciar o mínimo possível sobre o sistema de formação de preços. A ofensa a estas premissas implica na ineficiência geral do sistema econômico.

Para entendermos melhor este princípio torna-se necessária a análise da influência

${ }^{34}$ Cf. Bérgson, Abram. A Reformulation of Certain Aspects of Welfare Economics. Quarterly Journal of Economics. 1938. 
que exerce a tributação no equilíbrio geral do sistema, ou seja, sobre as decisões dos agentes e na formação de preços. A percepção dos agentes gera distorções na coordenação eficiente dos agentes, assim, por exemplo, os consumidores percebem os preços após a incidência da tributação (“after-tax prices”), enquanto que os produtores os percebem antes da tributação ("before-tax prices”). Não há como ocorrer uma ação coordenada, visto que os agentes percebem diferentemente os sinais enviados pelo mercado ${ }^{35}$.

Os efeitos gerais da tributação podem divididos da seguinte forma quanto aos tributos sobre: i) a renda; ii) capital; iii) consumo e iv) folha de pagamentos.

i) Os efeitos gerais da tributação a renda das pessoas físicas.

A tributação da renda afeta a oferta de mão-de-obra, em um primeiro sentido diminuindo a renda e, em consequência, implicando em uma diminuição da demanda por tempo livre ("leisure”) e implica em uma oferta maior de força de trabalho. A redução de salários, pelo aumento da oferta de força de trabalho, por sua vez, diminui novamente a renda e por conseguinte tornando menos atrativa a oferta de trabalho, incentivando o suprimento de atividades no setor informal da economia, em tempo integral ou parcial, dado que este é um setor não-tributado ${ }^{36}$.

A tributação, nesse sentido, deve agir de modo a influenciar o mínimo possível a oferta de trabalho, sem estimular o mercado informal, reduzindo o mínimo a renda pessoal.

ii) Os efeitos gerais da tributação o capital.

O aumento de preços decorrentes da tributação implica em dois efeitos: a) efeito sobre a renda, visto que o aumento de preços de implica em um estímulo à poupança e b) efeito de substituição, dado que o aumento dos preços torna no futuro o consumo mais caro, reduzindo a poupança realizada em um primeiro momento ${ }^{37}$. Este mesmo efeito pode ser observado na diminuição da poupança (riqueza acumulada) sob a forma de patrimônio ou na herança (“bequests”). Igualmente, a tributação irá influenciar a tomada de decisões dos agentes econômicos na tomada de certos riscos.

A tributação, desse modo, deve procurar incentivar a poupança, mas também não provocar um efeito posterior de retirada do estímulo da poupança pelo aumento de preços. Desse modo, a tributação progressiva com alíquotas decrescentes, ou seja, menor quanto maior o tempo passar entre a aplicação e o resgate, parece ser a solução ideal.

iii) Os efeitos gerais da tributação o consumo.

Os efeitos da tributação sobre o consumo dependem de capacidade de realizarem escolhas econômicas e mudanças de comportamento (elasticidade). Desse modo, quanto menor for a possibilidade de alterar minhas escolhas e mudar meu comportamento menor será a elasticidade desta situação. Dessa forma: a) se a demanda possuir maior

${ }^{35}$ Cf. Bérgson, Abram. A Reformulation of Certain Aspects of Welfare Economics. Quarterly Journal of Economics. 1938, p. 35.

${ }^{36}$ Idem, p. 38 e 44.

${ }^{37}$ Idem, p. 46. 
elasticidade do que a oferta, então tributação sobre o consumo influenciará pouco o preço ao consumidor e, portanto, os produtores carregarão todo o peso da tributação ${ }^{38}$.

Se por outro lado, a oferta possuir maior elasticidade do que a demanda, então o peso da tributação sobre o consumo será transferido diretamente para o consumidor. A regra poderia ser explicada da seguinte forma: a parte do ciclo econômico (produção ou consumo) que possuir menor flexibilidade para alterar o seu comportamento econômico e não puder realizar escolhas alternativas irá suportar a maior parte do peso da tributação.

A neutralidade fiscal deve ser alcançada, assim, diminuindo os efeitos da tributação sobre setores rígidos, de modo a não criar ineficiências no sistema, provocando um enfraquecimento do lado da oferta (produção) ou do consumidor, o que em longo prazo pode implicar em sérias distorções no sistema produtivo ou na renda geral da sociedade.

\section{CONSIDERAÇÕES FINAIS}

O estudo das contribuições da análise econômica do Direito e, especialmente, do Direito Tributário ainda é um tema recente para a literatura jurídica. Entendemos, contudo, que podemos afirmar que existe uma importância real para a compreensão do fenômeno jurídico da tributação e que existem aplicações práticas para o desenvolvimento do Direito Tributário e da política fiscal. Apesar dos grandes avanços desde os trabalhos seminais de Ronald Coase até os estudos de Richard Posner, James Buchanan, Mises e Douglass North, não podemos afirmar ainda que existam trabalhos específicos sobre a sua aplicação ao fenômeno tributário.

Como certeza existem limites à esta aplicação, bem como muitos elementos a avançar nesta agenda de trabalho, contudo, cremos da importância significativa deste estudo para a construção de uma modelo de tributação mais justo e eficiente.

\section{REFERÊNCIAS BIBLIOGRÁFICAS}

Textos Básicos.

ALVAREZ, Alejandro Bugallo. Análise econômica do direito: contribuições e desmistificações. Revista Direito, Estado e Sociedade. no 29, jul./dez. 2006, p. 49-68.

BOUCKAERT, Boudewijn et GEEST, Gerrit De. Encyclopedia of Law And Economics, Volumes I-V. Publicação online disponível em http://encyclo.findlaw.com. Acesso em 6 ago. 2007 às 14 horas.

CALIENDO, Paulo. Direito Tributário e Análise Econômica do Direito. Rio de Janeiro: Elsevier, 2008.

COOTER, Robert et and Ulen, Thomas. Introduction to Law and Economics. New York: Addison Wesley Longman 2000.

Textos complementares.

BUCHANAN, James. Public Finance in Democratic Process: Fiscal Institutions and Individual Choice. Item 4.1.3. Disponível em http://www.econlib.org/library/buchanan/buchCv5Contents.html. Acesso em 2 ago. 2006, às 18 horas.

${ }^{38}$ Cf. Bérgson, Abram. A Reformulation of Certain Aspects of Welfare Economics. Quarterly Journal of Economics. 1938, p. 19.

DIREITOS FUNDAMENTAIS E JUSTIÇA N 7 -ABR./JUn. 2009 
BUCHANAN, James. The Constitucion of Economic Policy. American Economic Review, Vol. 77, no 3 (Jun. 1987), pp. 243-250.

COASE, R. Industrial Organization: a proposal for research. In Victor R. Fuchs (ed.) Policy issues and research opportunities in Industrial Organization. New York: National Bureau of Economic Research, 1972, p. 59-73.

COASE, Ronald. The Problem of Social Cost. Journal of Law and Economics. Vol. 3 (October 1960), pp. 1-44.

HAYEK, Friedrich A. Law, Legislation and Liberty, Volume I: Rules and Order. Chicago: University of Chicaqo Press, 1973.

HAYEK, Friedrich A. The Constitution of Liberty. Chicago: University of Chicago Press, 1960.

NORTH, Douglass. Institutions, Institutional Change and Economic Performance. Cambridge: Cambridge Press, 1990.

POSNER, Richard. The problems of Jurisprudence. Boston: Harvard, 1993.

WILLIAMSON, Oliver E. The New Institutional Economics: Taking Stock, Looking Ahead. Journal of Economic Literature, Vol. XXXVIII (September 2000) pp. 595-613. 